\title{
Investigation of electronic structure of amorphous niobium oxide based on the density functional theory calculation of crystalline niobium pentoxide polymorphs
}

\author{
Chinatsu OKI, Go SAJIKI, ${ }^{*}$ Shinichi SAKIDA, Yasuhiko BENINO ${ }^{\dagger}$ and Tokuro NANBA \\ Graduate School of Environmental and Life Science, Okayama University, \\ 3-1-1 Tsushima-Naka, Kita-ku, Okayama 700-8530, Japan \\ *Technological, Educational Supporting Center in Takamatsu, Kagawa National College of Technology, \\ 355 Chokushi-cho, Takamatsu 761-8058, Japan
}

\begin{abstract}
Electronic structure of amorphous niobium oxide prepared by a sputtering method was investigated based on optical absorption and photoelectron spectroscopies. In the valence band photoelectron spectra, broad peaks without any characteristic components were observed. Then, theoretical calculations based on a density functional theory were performed to interpret the experimental spectra by using three $\mathrm{Nb}_{2} \mathrm{O}_{5}$ polymorphs. Among the polymorphs, M-phase with tetragonal structure showed better reproducibility than the other B- and R-phases with monoclinic structure. It was finally concluded that the amorphous niobium oxide had a similar electronic structure to $\mathrm{M}-\mathrm{Nb}_{2} \mathrm{O}_{5}$, and it was supposed that the broad feature in the photoelectron spectra was due to the broad distribution of $\mathrm{Nb}-\mathrm{O}$ bonds in $\mathrm{NbO}_{6}$ polyhedra, which was characteristic in $\mathrm{M}-\mathrm{Nb}_{2} \mathrm{O}_{5}$.

(C2016 The Ceramic Society of Japan. All rights reserved.
\end{abstract}

Key-words : Niobium oxide, Electronic structure, Photoelectron spectrum, Optical absorption spectrum, Density functional theory calculation

[Received August 10, 2016; Accepted October 9, 2016]

Niobium pentoxide is known as wide-gap semiconductor ${ }^{1)}$ and dielectric, ${ }^{2)-4)}$ which is expected for the application such as catalyst, ${ }^{5,, 6)}$ sensor, ${ }^{7), 8)}$ etc. In particular, it is widely used as a capacitor $^{9), 10)}$ in general products. Among rare metal elements, niobium is comparatively abundant, and hence materials derived from niobium compounds are supposed to be advantageous in regards to cost. ${ }^{11)}$ In the authors' research group, a photoelectrochemical cell (PEC) with $\mathrm{NbO}_{x} / \mathrm{Al} /$ glass $\mid \mathrm{KNO}_{3}$ aq.|Al/ glass has been developed, ${ }^{12)}$ where small but stable power generation was observed. Niobium oxide, $\mathrm{NbO}_{x}$ was deposited by an RF-magnetron sputtering method, and larger output was obtained when the $\mathrm{NbO}_{x}$ deposits were not in film, but in a nano-island structure. Analysis on the electronic states of the $\mathrm{NbO}_{x}$ deposits are indispensable to clarify the photovoltaic conversion mechanism and improve power generation. However, the deposits are amorphous so that it is quite difficult to clarify the electronic structure.

Then, in the present study, information of electronic structure was obtained by X-ray and ultraviolet photoelectron spectroscopies (XPS and UPS) and optical absorption. The experimental spectra were interpreted by using theoretical calculations based on density functional theory (DFT), ${ }^{13), 14)}$ where crystalline $\mathrm{Nb}_{2} \mathrm{O}_{5}$ were used for the DFT calculations. A DFT calculation of B-phase $\mathrm{Nb}_{2} \mathrm{O}_{5}$ was published. ${ }^{15)}$ However, $\mathrm{Nb}_{2} \mathrm{O}_{5}$ has various polymorphs with different structures, and hence a large variety in the electronic structure is expected in the polymorphs. DFT calculations for various polymorphs, instead of those for amorphous structure with major difficulties, should give valuable information for the similarity and variation of local structures in the amor-

Corresponding author: Y. Benino; E-mail: benino@okayama-u. ac.jp phous solid. Consequently, three $\mathrm{Nb}_{2} \mathrm{O}_{5}$ crystals with typical structures were chosen to investigate the electronic structure of $\mathrm{Nb}_{2} \mathrm{O}_{5}$ polymorphs. By comparing the experimental and simulated spectra, structure of amorphous $\mathrm{NbO}_{x}$ deposit was discussed.

$\mathrm{NbO}_{x}$ film was prepared by an $\mathrm{RF}$ magnetron sputtering method. The detailed preparing condition was given in Ref. 12 . Optical absorption spectra have been measured for the films deposited on a quartz glass substrate with different sputtering time. XPS and UPS spectra were also measured to estimate the valence band structure of the amorphous $\mathrm{NbO}_{x}$ film, where the $\mathrm{NbO}_{x}$ film was deposited on an ITO-coated glass substrate. XPS and UPS spectra were measured by irradiating Al-K $\alpha$ (1486.6 $\mathrm{eV})$ and He I $(21.22 \mathrm{eV})$ lines, respectively. In XPS, binding energy was corrected by using a $\mathrm{C} 1 \mathrm{~s}$ peak $(284.6 \mathrm{eV})$ and $\mathrm{Au}$ $4 \mathrm{f}_{7 / 2}(84.0 \mathrm{eV})$.

DFT calculations were performed by using the WIEN2k code ${ }^{16)}$ to interpret the experimental spectra. $\mathrm{Nb}_{2} \mathrm{O}_{5}$ polymorphs of B-, ${ }^{17), 18)} \mathrm{R}-,{ }^{19), 20)}$ and M-phases ${ }^{21)}$ were selected for the DFT calculation. For the exchange-correlation functional, the generalized gradient approximation with the Perdew-Burke-Ernzerhof $(\mathrm{PBE})^{22)}$ was used. The Kohn-Sham equations were solved with the linearized augmented plane wave (LAPW) method. ${ }^{23)}$ Brilloin-zone integration was performed on a Monkhorst-Pack

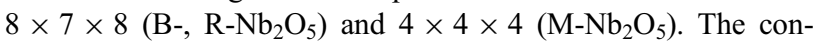
vergence is controlled by a cut-off parameter $R_{\mathrm{mt}} K_{\max }=7.00$, where $R_{\mathrm{mt}}$ and $K_{\max }$ are the smallest atomic sphere radius in the unit cell and the magnitude of the largest $\mathbf{k}$ vector, respectively, and the total energy converged less than $0.10 \mathrm{mRy}$. Fermi-level determination and $\mathbf{k}$-space integration was done by the modified tetrahedron method.

XPS and UPS spectra were estimated by multiplying projected DOS (PDOS) by photoionization cross-section of atomic 
(a) $\mathrm{B}-\mathrm{Nb}_{2} \mathrm{O}_{5}$

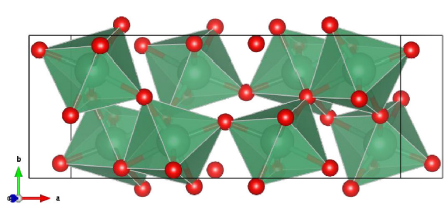

(b) $\mathrm{R}-\mathrm{Nb}_{2} \mathrm{O}_{5}$

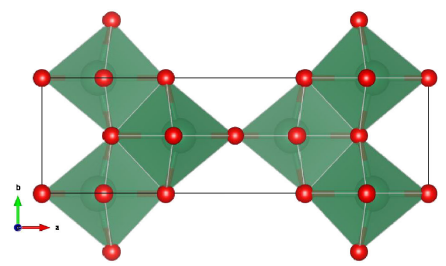

Fig. 1. Crystal structures of (a) B-, (b) R-, and (c) M-phases of $\mathrm{Nb}_{2} \mathrm{O}_{5}$.

(c) $\mathrm{M}-\mathrm{Nb}_{2} \mathrm{O}_{5}$

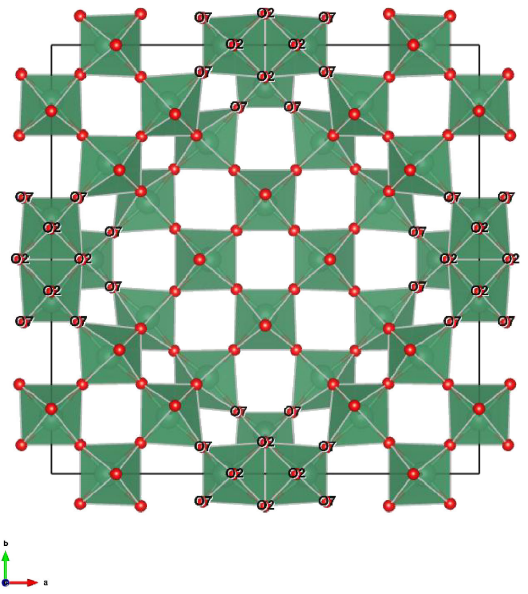

(c) $\mathrm{M}-\mathrm{Nb}_{2} \mathrm{O}_{5}$

(a) $\mathrm{B}-\mathrm{Nb}_{2} \mathrm{O}_{5}$
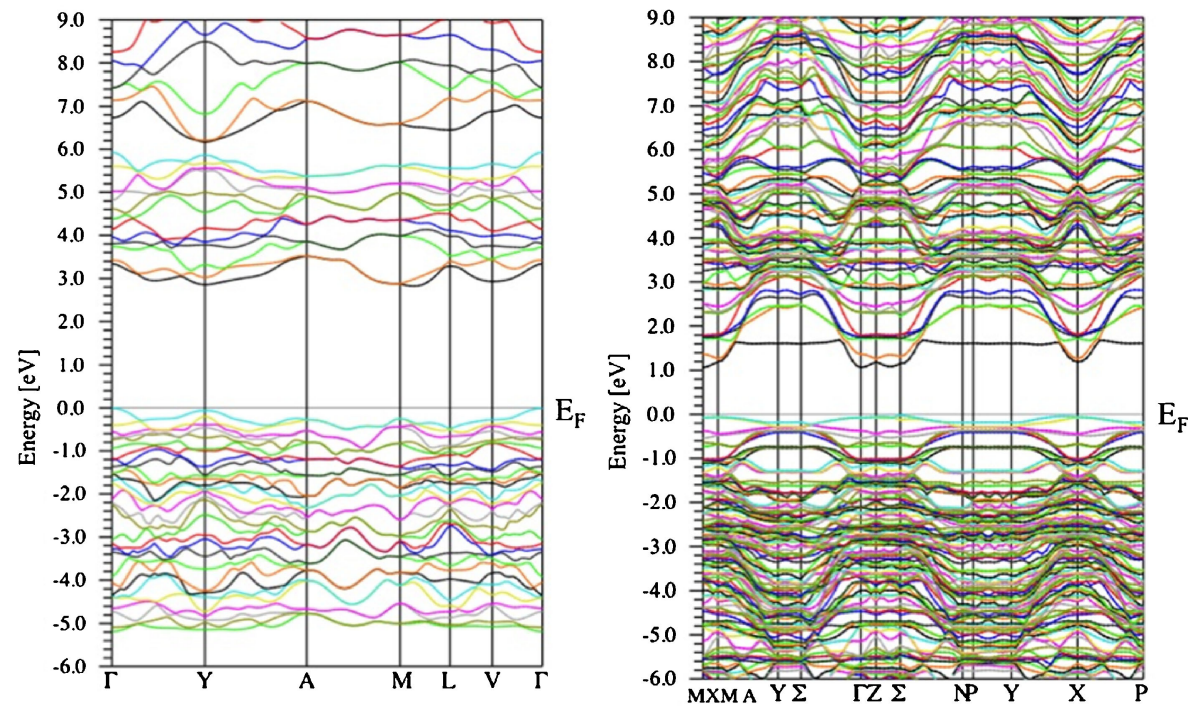

(b) $\mathrm{R}-\mathrm{Nb}_{2} \mathrm{O}_{5}$

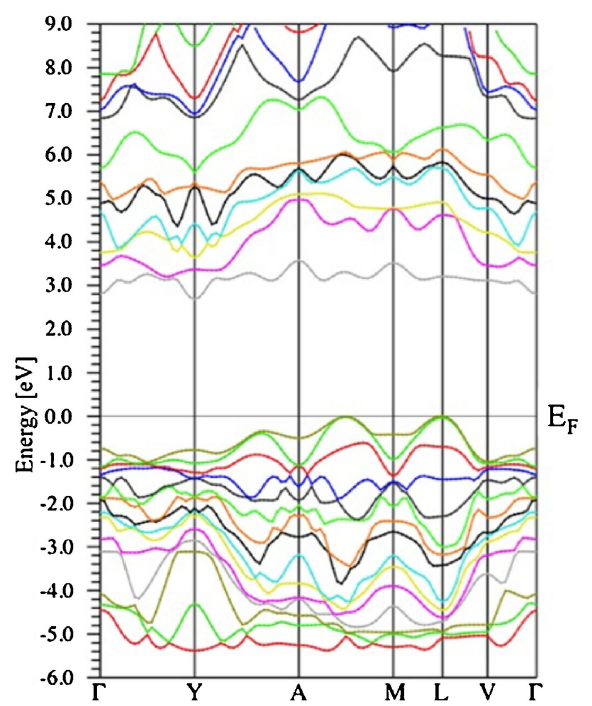

Fig. 2. Band diagrams of (a) B-, (b) R-, and (c) M-phases of $\mathrm{Nb}_{2} \mathrm{O}_{5}$ obtained from DFT calculations. The colors have no physical meaning. 
orbitals. ${ }^{24)}$ Optical absorption depends on the imaginary part of dielectric tensor, and hence experimental absorption spectrum was compared with the imaginary part of dielectric tensor.

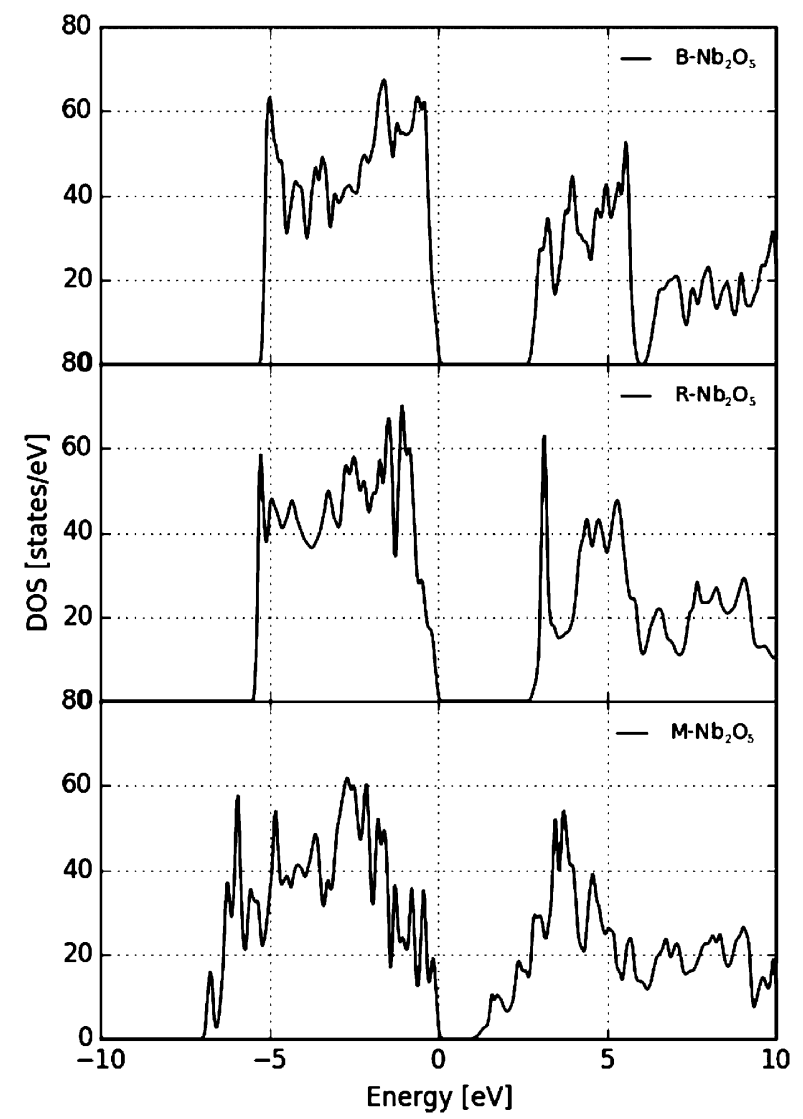

Fig. 3. Total density of states of B-, R-, and M-phases of $\mathrm{Nb}_{2} \mathrm{O}_{5}$ obtained from DFT calculations.

(a) $\mathrm{B}-\mathrm{Nb}_{2} \mathrm{O}_{5}$

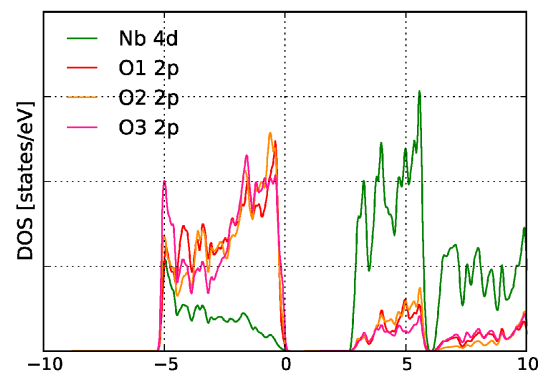

(b) $\mathrm{R}-\mathrm{Nb}_{2} \mathrm{O}_{5}$

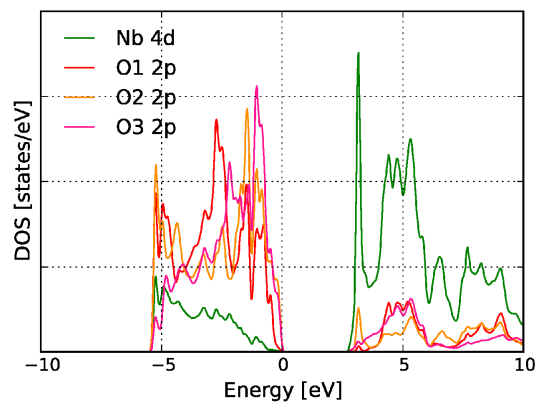

Dielectric function is a complex function, $\varepsilon(\omega)=\varepsilon_{1}+i \varepsilon_{2}$, where the imaginary part of the dielectric function, $\varepsilon_{2}(\omega)$ is given by

$$
\begin{aligned}
\varepsilon_{\alpha \beta}^{(2)}(\omega)= & \frac{4 \pi^{2} e^{2}}{\Omega_{0}} \lim _{q \rightarrow 0} \frac{1}{q^{2}} \sum_{c, v, \mathbf{k}} 2 w_{\mathbf{k}} \delta\left(\varepsilon_{c \mathbf{k}}-\varepsilon_{v \mathbf{k}}-\omega\right) \\
& \times\left\langle u_{c \mathbf{k}+\hat{e}_{\alpha} q} \mid u_{v \mathbf{k}}\right\rangle\left\langle u_{c \mathbf{k}+\hat{e}_{\beta} q} \mid u_{v \mathbf{k}}\right\rangle^{*}
\end{aligned}
$$

where $e$ is the electron charge, $\Omega_{0}$ is the volume of the primitive cell, $q$ denotes the Bloch vector of the incident wave. $w_{\mathbf{k}}$ are the k-point weights defined such that they sum to 1 , and the $v$ and $c$ subindices denote valence and conduction band states, respectively. $\varepsilon_{c \mathbf{k}}$ and $\varepsilon_{v \mathbf{k}}$ are the Kohn-Sham eigenvalues, $\omega$ is the frequency, $u_{c \mathbf{k}}$ and $u_{v \mathbf{k}}$ are the wave functions, and $\hat{e}_{\alpha}$ and $\hat{e}_{\beta}$ are the unit vector for the three Cartesian directions. ${ }^{15), 25)}$

Structures of $\mathrm{Nb}_{2} \mathrm{O}_{5}$ crystals used for the DFT calculation are shown in Fig. 1. In these crystals, distorted $\mathrm{NbO}_{6}$ octahedra connect with others sharing their corners and edges. $\mathrm{B}-\mathrm{Nb}_{2} \mathrm{O}_{5}$ phase is the most stable phase under ambient condition, and Rand M-phases are meta-stable. ${ }^{26)}$ The band diagrams of B-, R-, and $\mathrm{M}-\mathrm{Nb}_{2} \mathrm{O}_{5}$ phases are shown in Fig. 2. Total density of states (TDOS) are shown in Fig. 3. TDOSs of B- and R-phases show similar feature, in which valence band maximum (VBM) and conduction band minimum (CBM) have steep edges. VBM and $\mathrm{CBM}$ edges of M-phase are, however, comparatively gentle in slope. The band gap energies of B-, R-, and M-phases are 2.42, 2.67, and $0.73 \mathrm{eV}$, respectively. In PDOSs shown in Fig. 4, s orbitals of $\mathrm{Nb}$ and $\mathrm{O}$ have negligibly small contribution, and hence they are omitted in Fig. 4. Larger contributions of $\mathrm{O} p$ and $\mathrm{Nb} \mathrm{d}$ orbitals are confirmed in VBM and CBM, respectively. In these region, bands consist mostly of $\mathrm{O} 2 \mathrm{p}$ and $\mathrm{Nb} 4 \mathrm{~d}$. If $\mathrm{Nb}$ atoms are in a valence state of $5+, \mathrm{Nb} 4 \mathrm{~d}$ orbital must be vacant. The negligible contribution of $\mathrm{Nb} 4 \mathrm{~d}$ in the valance band indicates that the effective valence state is lower than $5+$, which is due to the covalency in the chemical bonding characteristics of $\mathrm{Nb}_{2} \mathrm{O}_{5}$. In $\mathrm{M}-\mathrm{Nb}_{2} \mathrm{O}_{5}$, oxygens in $\mathrm{O} 2$ and $\mathrm{O} 7$ sites show different

(c) $\mathrm{M}-\mathrm{Nb}_{2} \mathrm{O}_{5}$
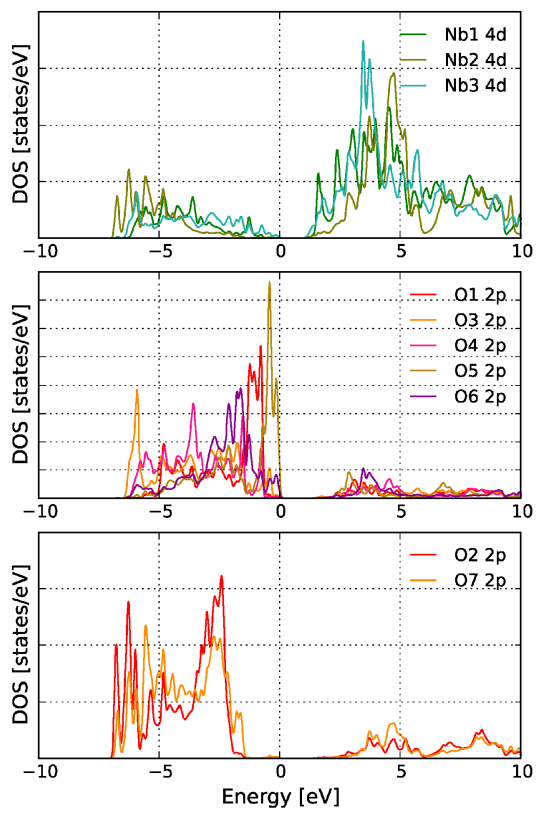

Fig. 4. Projected density of states of (a) B-, (b) R-, and (c) M-phases of $\mathrm{Nb}_{2} \mathrm{O}_{5}$ obtained from DFT calculations. 
(a) XPS

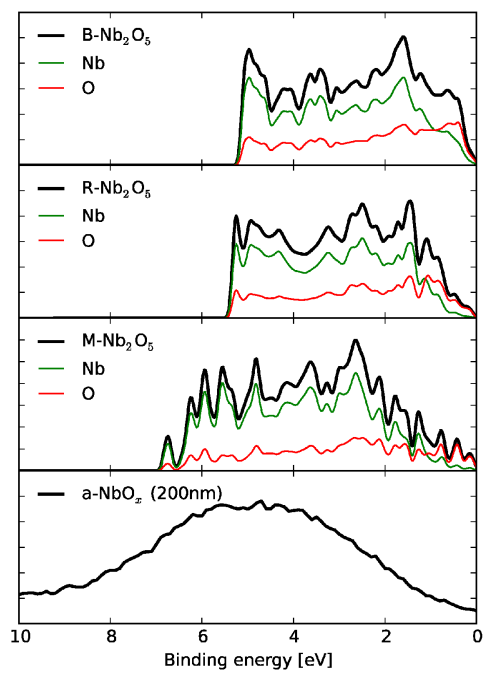

(b) UPS

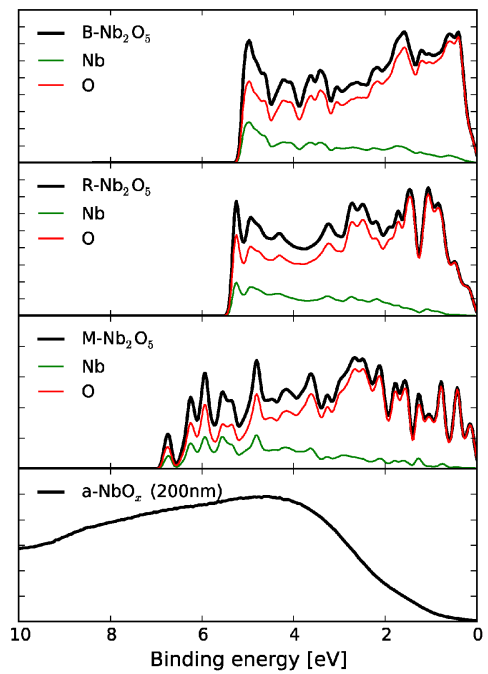

Fig. 5. (a) XPS and (b) UPS of B-, R-, and M-phases of $\mathrm{Nb}_{2} \mathrm{O}_{5}$ obtained from DFT calculations and experimental spectra of amorphous $\mathrm{NbO}_{x}$.

(a) $\mathrm{B}-\mathrm{Nb}_{2} \mathrm{O}_{5}$

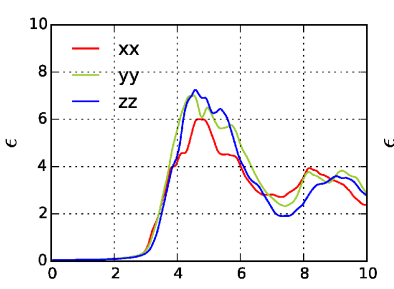

(b) $\mathrm{R}-\mathrm{Nb}_{2} \mathrm{O}_{5}$

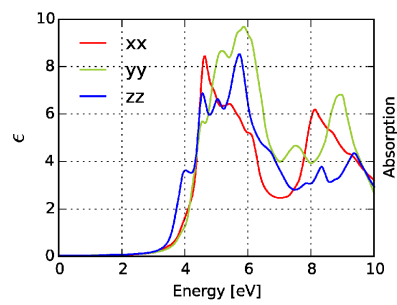

(c) $\mathrm{M}-\mathrm{Nb}_{2} \mathrm{O}_{5}$

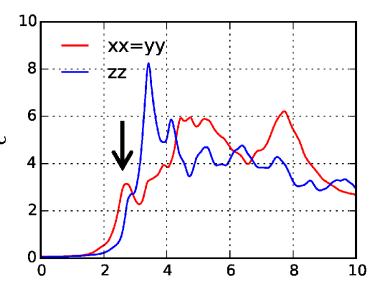

(d) $\mathrm{a}-\mathrm{NbO}_{\mathrm{x}}$

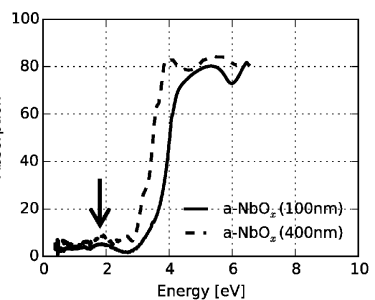

Fig. 6. Imaginary part of the dielectric function, $\varepsilon_{2}$ of (a) B-, (b) R-, and (c) M-phases of $\mathrm{Nb}_{2} \mathrm{O}_{5}$ obtained from DFT calculations and (d) experimental optical absorption spectra of amorphous $\mathrm{NbO}_{x}$.

contribution in PDOS from the other oxygen sites, where $\mathrm{O} 2$ and $\mathrm{O} 7$ sites have larger energy gap ca. $6 \mathrm{eV}$. For $\mathrm{O} 2$ and $\mathrm{O} 7$ sites, $\mathrm{Nb}-\mathrm{O}$ bonds have shorter $(0.16 \mathrm{~nm})$ and longer $(0.25 \mathrm{~nm})$ lengths as compared with other $\mathrm{Nb}-\mathrm{O}$ bonds $(0.18-0.22 \mathrm{~nm})$. The difference in bond length distribution may be responsible for the different shape of DOS in valence and conduction bands.

Figure 5 shows XPS and UPS spectra. The experimental spectra are broad, and any characteristic components are not recognized. In the spectra calculated from PDOSs, contribution of $\mathrm{Nb} \mathrm{d}$ orbital is larger than that of $\mathrm{O} p$ orbital in XPS and smaller in UPS, which is due to the much larger photoionization cross-section of $\mathrm{Nb} 4 \mathrm{~d}$ than $\mathrm{O} 2 \mathrm{p}$ for $\mathrm{Al}-\mathrm{K} \alpha$ irradiation. ${ }^{24)} \mathrm{M}$ phase shows gentle edges at both maximum and minimum of valence band in XPS and UPS, which is similar to the experimental spectra of amorphous $\mathrm{NbO}_{x}$.

Figure 6 shows imaginary part of the dielectric function, $\varepsilon_{2}$ obtained from DFT calculations. B- and R-phases are monoclinic $\left(\varepsilon_{\mathrm{xx}} \neq \varepsilon_{\mathrm{yy}} \neq \varepsilon_{\mathrm{zz}}\right)$, and M-phase is tetragonal $\left(\varepsilon_{\mathrm{xx}}=\varepsilon_{\mathrm{yy}} \neq \varepsilon_{\mathrm{zz}}\right)$.

For B- and R-phases of $\mathrm{Nb}_{2} \mathrm{O}_{5}$, two major components are confirmed at $\sim 5$ and $\sim 9 \mathrm{eV}$, where both components are assigned to the transition from $\mathrm{O} 2 \mathrm{p}$ to $\mathrm{Nb} 4 \mathrm{~d}$ orbitals. In M-phase, $\varepsilon_{\mathrm{xx}}$ and $\varepsilon_{\mathrm{zz}}$ are different, and a stronger peak is observed at $\sim 3.5 \mathrm{eV}$ in $\varepsilon_{\text {zz. }}$. In TDOS (Fig. 3), M-phase has smaller band gap, and in $\varepsilon_{2}$, the gap (apparent optical band gap) is wider than that of TDOS. As is also indicated from band diagram (Fig. 2), $\mathrm{Nb}_{2} \mathrm{O}_{5}$ polymorphs are indirect electron transition semiconductors. In the experimental spectra, a small peak is found at $\sim 2 \mathrm{eV}$, which is not an interference peak because the peak position is the same in the films with different thicknesses. In M-phase, small pre-edge peak [arrow in Fig. 6(c)] is confirmed at $\sim 2.5 \mathrm{eV}$, and the $2 \mathrm{eV}$ small peak in the experimental spectra may [arrow in Fig. 6(d)] be originated in the pre-edge peak in $\mathrm{M}-\mathrm{Nb}_{2} \mathrm{O}_{5}$. This is just a speculation, and further detailed analyses are needed to the actual interpretation.

In this study, electronic structure of amorphous $\mathrm{NbO}_{x}$ film prepared by RF-magnetron sputtering method was investigated. The experimental photoelectron spectra of a- $\mathrm{NbO}_{x}$ were broad, and no characteristic components were confirmed. DFT calculations of some $\mathrm{Nb}_{2} \mathrm{O}_{5}$ polymorphs were performed to interpret the photoelectron and optical absorption spectra. Among the phases investigated, $\mathrm{M}-\mathrm{Nb}_{2} \mathrm{O}_{5}$ showed better reproducibility of the experimental spectra, suggesting that $\mathrm{a}-\mathrm{NbO}_{x}$ had a similar electronic and also local structure to $\mathrm{M}-\mathrm{Nb}_{2} \mathrm{O}_{5}$, which was originated from the broad distribution of $\mathrm{Nb}-\mathrm{O}$ bond length in $\mathrm{NbO}_{6}$ polyhedra characteristic in $\mathrm{M}-\mathrm{Nb}_{2} \mathrm{O}_{5}$. However, other polymorphs not investigated in this study are present in $\mathrm{Nb}_{2} \mathrm{O}_{5}$, and also the electronic-structure estimation for a-NbO $\mathrm{N}_{x}$ itself is not yet accomplished. Since the valence state of $\mathrm{Nb}$ in $\mathrm{a}-\mathrm{NbO}_{x}$ is still obscure at present, further experiments and investigation are indispensable to elucidate the electronic structure of a- $\mathrm{NbO}_{x}$ and to clarify the photovoltaic conversion mechanism of a- $\mathrm{NbO}_{x}$ based PEC. Structural modeling of a-NbO $\mathrm{N}_{x}$ based on high precision structural analyses and succeeding quantum chemistry calculations for them will establish a valid methodology for this purpose in the near future.

\section{References}

1) M. H. Habibi and R. Mokhtari, J. Sol-Gel Sci. Technol., 59, 352-357 (2011). 
2) C. Nico, M. R. N. Soares, J. Rodriguez, M. Matos, R. Monteiro, M. P. F. Graça, M. A. Valente, F. M. Costa and T. Monteiro, J. Phys. Chem. C, 115, 4879-4886 (2011).

3) S. Clima, G. Pourtois, A. Hardy, S. V. Elshocht, M. K. V. Bael, S. D. Gendt, D. J. Wouters, M. Heyns and J. A. Kittl, J. Electrochem. Soc., 157, G20-G25 (2010).

4) H. Störmer, A. Weber, V. Fischer, E. Ivers-Tiffée and D. Gerthsen, J. Eur. Ceram. Soc., 29, 1743-1753 (2009).

5) I. Nowak and M. Ziolek, Chem. Rev., 99, 3603-3624 (1999).

6) E. Ko and J. Weissman, Catal. Today, 8, 27-36 (1990).

7) A. Kohli, C. C. Wang and S. A. Akbar, Sens. Actuators, B, 56, 121-128 (1999).

8) M. E. Gimon-Kinsel and K. J. Balkus, Jr., Microporous Mesoporous Mater., 28, 113-123 (1999).

9) J. E. Yoo and J. Choi, Electrochem. Commun., 13, 298-301 (2011).

10) K. Kim, J. Park, G. Cha, J. E. Yoo and J. Choi, Mater. Chem Phys., 141, 810-815 (2013).

11) T. Okabe, Kinzoku, 72, 202-203 (2002)

12) G. Sajiki, Y. Benino, T. Nanba and H. Okano, Materials Sciences and Applications, 6, 292-309 (2015).

13) W. Kohn and L. J. Sham, Phys. Rev., 140, A1133-A1138 (1965).

14) P. Hohenberg and W. Kohn, Phys. Rev., 136, B864-B871 (1964).
15) S. Pérez-Walton, C. Valencia-Balvín, G. M. Dalpian and J. M. Osorio-Guillén, Phys. Status Solidi B, 250, 1644-1650 (2013).

16) P. Blaha, K. Schwarz, G. K. H. Medsen, D. Kvasnicka and J. Luitz, WIEN2k, An Augmented Plane Wave + Local Orbitals Program for Calculating Crystal Properties, Karlheinz Schwartz, Techn. Universität Wien, Austria (2001).

17) F. Laves, W. Petter and H. Wulf, Naturwissenschaften, 51, 633-634 (1964).

18) T. S. Ercit, Mineral. Petrol., 43, 217-223 (1991).

19) R. Gruehn, J. Less-Common Met., 11, 119-126 (1966).

20) V. Plies and R. Gruehn, J. Less-Common Met., 42, 77-88 (1975).

21) W. Mertin, S. Andersson and R. Gruehn, J. Solid State Chem., 1, 419-424 (1970).

22) J. P. Perdew, S. Burke and M. Ernzerhof, Phys. Rev. Lett., 77, 3865-3868 (1996).

23) D. Koelling and B. Harmon, J. Phys. C Solid State Phys., 10, 3107-3114 (1977).

24) J. J. Yeh and I. Lidau, "Atomic Data and Nuclear Data Tables", 32, Academic Press, New York (1985) pp. 1-155.

25) M. Gajdoš, K. Hummer, G. Kresse, J. Furthmüller and F. Bechstedt, Phys. Rev. B, 73, 045112 (2006).

26) C. Valencia-Balvín, S. Pérez-Walton, G. M. Dalpian and J. M. Osorio-Guillén, Comput. Mater. Sci., 81, 133-140 (2014). 